\title{
La responsabilidad de mando en el Acuerdo de Paz y en la normativa interna de implementación
}

The command responsibility in the peace agreement and in the internal regulations of implementation

Autor: Yury Lineth Sierra Torres

DOI: https://doi.org/10.25058/1794600X.991

\footnotetext{
SP MISIÓN JURÍDICA A 


\title{
LA RESPONSABILIDAD DE MANDO EN EL ACUERDO DE PAZ Y EN LA NORMATIVA INTERNA DE IMPLEMENTACIÓN*
}

\author{
THE COMMAND RESPONSIBILITY IN THE \\ PEACE AGREEMENT AND IN THE INTERNAL \\ REGULATIONS OF IMPLEMENTATION
}

A RESPONSABILIDADE DO COMANDO NO
ACORDO DE PAZ E NOS REGULAMENTOS
INTERNOS DE IMPLEMENTAÇÃO

\section{RESUMEN}

En este artículo se hace un recuento general sobre la figura de la responsabilidad de mando, a partir del Acuerdo Final de Paz y en las normas que lo implementaron en el ordenamiento jurídico colombiano. El objeto del artículo es mostrar cómo la regulación de esta figura se fue desarrollando con unos vacíos preexistentes, y las preocupaciones que en torno a la misma se fueron dando por parte de la sociedad civil, académicos, organizaciones internacionales y, finalmente, la Corte Penal Internacional. Se muestra cómo la regulación inicial del Acuerdo se fue consolidando en la normativa interna, desatendiendo las advertencias de vacíos regulatorios que fueron allegadas al respecto.

*Artículo de reflexión.

a. Candidata a Maestría en Derecho con énfasis en Derechos Humanos y Justicia Transicional.

Para citar este artículo:

Sierra, Y. (2019). La responsabilidad de mando en el Acuerdo de Paz y en la normativa interna de implementación.

Fecha de recepción: septiembre 18 de 2018 Fecha de revisión: octubre 22 de 2018 Fecha de aceptación: octubre 27 de 2018 


\section{PALABRAS CLAVE}

Responsabilidad de mando, conocimiento, prevenir, reprimir, omisión.

\section{ABSTRACT}

In this article an overview on the figure of command responsibility is given from the Final Peace Agreement and the regulations that have been implemented in the Colombian legal system. The objective of this article is to show how the regulation of this figure has developed with pre-existing gaps and the concern that it has caused on the subject through civil society, scholars, international organizations; even the International Criminal Court, also revealing that the initial regulation of the Agreement has consolidated in the internal regulations, ignoring the warnings of regulatory gaps that had been noticed on this matter.

\section{KEYWORDS}

Key words: Command responsibility; knowledge; prevent; repress; omission.

\section{RESUMO}

Neste artigo, é feita uma recontagem geral da responsabilidade da figura de comando, com base no Acordo Final de Paz e nas normas de implementação no sistema legal colombiano. 0 objetivo do artigo é mostrar como a regulação dessa figura foi desenvolvida com algumas lacunas preexistentes, e as preocupações que a cercam foram dadas, a partir da sociedade civil, acadêmicos, organizações internacionais; até o Tribunal Penal Internacional, mostrando também que a regulamentação inicial do Acordo foi consolidada no regimento interno, desconsiderando os alertas de falhas regulatórias que estavam relacionados a esse respeito.

\section{PALAVRAS-CHAVE}

Responsabilidade do comando; conhecimento; prevenir; reprimir; omissão.

\section{INTRODUCCIÓN}

En materia penal se responde a los hechos delictivos no solo por acción sino también por omisión. Bajo determinadas circunstancias, la responsabilidad de mando es una de esas formas de responsabilidad por omisión derivada, en este caso, del incumplimiento de la obligación de prevenir, reprimir o castigar la comisión de delitos por parte de los subordinados.

Luego del desarme de uno de los principales actores del conflicto armado en Colombia, el principal reto en materia de justicia es evitar la impunidad en la mayor medida posible para los máximos responsables de los delitos más graves, los cuales forman parte de estructuras jerarquizadas. A pesar de que la figura de la responsabilidad de mando no está expresamente recogida en el ordenamiento jurídico colombiano —el Código Penal no la recoge, y la figura más cercana es la Comisión por Omisión-, la responsabilidad de mando cumple en este contexto un papel determinante por el control efectivo que deben ejercer los superiores sobre sus subordinados. Este papel es reforzado por las graves omisiones que se generaron durante el conflicto, lo que provocó la afectación de millones de civiles a los que el Estado no les brindó las garantías suficientes de protección de sus derechos humanos ${ }^{1}$.

A pesar de esto - y como veremos a lo largo de este trabajo, que introduce primero los estándares internacionales, para abordar a continuación la normativa interna-, las disposiciones que sobre responsabilidad de mando se han establecido en el Acuerdo Final para la Terminación del Conflicto y la Construcción de una Paz Estable y Duradera —en particular, en el punto cinco, relativo a las víctimas del conflicto en el que se crea el Sistema Integral de Verdad, Justicia, Reparación y Garantías de no Repetición-, y que a pesar de haber sido objeto de desarrollo constitucional y legislativo, presentan importantes vacíos en relación con los parámetros establecidos sobre este tipo de responsabilidad en el Derecho Penal Internacional y, en particular, en el artículo 28 del Estatuto de Roma, recientemente interpretado en la sentencia de primera instancia en el Caso Bemba².

1. Muestra de esto son las múltiples sentencias de la Corte Interamericana de Derecho Humanos, que declararon la responsabilidad del Estado colombiano por hechos ocurridos en el marco del conflicto armado verbi gracia, Masacre de Pueblo Bello VS Colombia, Masacres de Ituango VS Colombia, Masacre Mapiripán VS Colombia, 19 comerciantes VS Colombia, Masacre de la Rochela VS Colombia.

2. (Situation In The Central African Republic In The Case Of The Prosecutor V Jean Pierre Bemba Gombo, 2016) 


\section{RESPONSABILIDAD DE MANDO EN EL DERECHO INTERNACIONAL HUMANITARIO Y EN EL DERECHO PENAL INTERNACIONAL}

\subsection{Antecedentes de la Responsabilidad de Mando}

La responsabilidad de mando surge en el contexto del Derecho Internacional Penal y el Derecho Internacional Humanitario, con el objetivo de sancionar las omisiones de los superiores, bien sean militares o incluso civiles, por los actos de sus subordinados. A su vez, las legislaciones internas de diferentes países también han consagrado este tipo de responsabilidad que se considera de carácter omisivo.

No existe un concepto unívoco sobre el origen de la responsabilidad de mando. No obstante, su desarrollo jurisprudencial inició con las sentencias de los Tribunales Militares Penales Internacionales creados después de la Segunda Guerra Mundial. En este sentido, la responsabilidad del superior tuvo un manejo diferente en la jurisprudencia de Nuremberg y Tokio, respectivamente. Como lo refiere Ambos (2005), en Nuremberg la responsabilidad disminuía en el mismo nivel en el que disminuía el control. Por otra parte, en Tokio la responsabilidad se extendió al Gobierno como colectivo y a sus miembros.

El caso más emblemático del Tribunal Militar Penal Internacional de Tokio fue el del general Yamashita, quien fue condenado a pena de muerte por los excesos de las fuerzas japonesas en Manila. Su defensa alegó que el general no se encontraba en el lugar de los hechos y que, además, sus comunicaciones habían sido completamente interrumpidas. Aun así, la sentencia contra él se hizo efectiva en medio de una gran polémica, toda vez que, para algunos críticos del fallo, este se basó más en razones de tipo racial (Ambos, 1999).

Por su parte, en el Tribunal Militar Penal Internacional para Nuremberg, vale la pena destacar los casos EE.UU. vs. Von List (1948) y EE.UU. vs. Von Leeb (1948). En el primero se estableció la responsabilidad de los superiores por los hechos cometidos dentro del territorio de su competencia y el deber de conocimiento de estos hechos. Ahora bien, en el caso contra Von Leeb, la exigencia del elemento de la responsabilidad se limitó, bajo la premisa de que "la comisión del delito no liga a todos los individuos de la cadena de mando por este solo hecho. Debe existir un descuido personal" (US V VON LEEB, CASO N 72). Es decir, el tribunal relacionaba el concepto de Responsabilidad de Mando directamente con la negligencia.

\subsection{Elementos de la Responsabilidad de Mando}

Antes de empezar a analizar los elementos que ha definido el Derecho Internacional Humanitario y el Derecho Internacional de los Derechos Humanos, vale la pena mencionar cómo, de acuerdo con Jakobs,

(...) el dominio del hecho, no es el único criterio para la determinación de la autoría; junto a éste está el deber especial. Pero ¿cómo puede construirse un concepto unitario de autor con un dominio y un deber? (...) la atribución normativa es de superior jerarquía que el dominio, este en todo caso determina la cantidad de una intervención delictiva (2000: 89).

La responsabilidad del mando o del superior refleja con claridad la denominada "crisis" del dominio del hecho, al determinar una serie de responsabilidades en cabeza del superior, cuya responsabilidad en el hecho punible se determina por acción y por omisión, bajo los criterios que se analizarán a continuación.

En 1977, el Protocolo I adicional a los Convenios de Ginebra estableció —en el artículo 86, numeral 2- la responsabilidad penal y disciplinaria de los superiores por los hechos de los subordinados. Respecto al conocimiento de los hechos, se consagró en este instrumento la expresión "si estos sabían o poseían información que les permitiera concluir", avanzando así en la responsabilidad del superior, no sólo por el conocimiento real; sino ahora bajo un tipo de conocimiento constructivo que fue desarrollado posteriormente en los Tribunales Penales Internacionales ad hoc.

En los Estatutos de los Tribunales Penales Internacionales, para la Ex Yugoslavia y Ruanda, se definió de forma similar la responsabilidad de mando. El artículo 7으 del Estatuto del Tribunal Penal Internacional para la ex Yugoslavia estableció la responsabilidad de los superiores por los hechos de los subordinados - “si sabía o tenía 
razones para saber" - sobre el acto a cometer o ya cometido, y no se tomaron las medidas para evitar la conducta o reprimirla. Por su parte, el artículo 6을 del Estatuto del Tribunal Internacional Penal para Ruanda trae una redacción casi similar relativa a la responsabilidad de los superiores, bajo la premisa del conocimiento efectivo o constructivo y el deber de tomar las medidas "necesarias y razonables" para impedir el hecho o castigar a los perpetradores.

Con base en la jurisprudencia de los Tribunales ad hoc, se han configurado los elementos constitutivos de la Responsabilidad de Mando, bajo los siguientes presupuestos:

1. Que exista una relación superior - subordinado.

2. Que el superior conozca o tenga razones para conocer sobre la comisión de un crimen que se va a cometer o que fue cometido por parte de sus subordinados.

3. Que el superior no tome las medidas necesarias y razonables para impedir los actos o para sancionar a los culpables. (TRIBUNAL PENAL INTERNACIONAL PARA LA EX YUGOSLAVIA, 1998).

El Estatuto de la Corte Especial para Sierra Leona mantuvo, en su artículo 6을 la Responsabilidad del Superior con los mismos elementos de los Tribunales de Ruanda y Yugoslavia bajo la premisa del conocimiento real y el conocimiento constructivo, con el presupuesto de que el autor de los hechos:

(...) sabía o tenía motivos para saber que el subordinado estaba a punto de cometer tales actos o lo había hecho y el superior no había tomado las medidas necesarias y razonables para prevenir tales actos o castigar a los autores de los mismos (Naciones Unidas [UN], 2000).

En lo relativo al Estatuto de Roma de la Corte Penal Internacional, el artículo 28 consagró la responsabilidad de los jefes y otros superiores, que, según Ambos (2005), contiene cinco elementos objetivos de la responsabilidad de mando, a saber:

1. La existencia de un superior y la relación de subordinación.

2.El mando y control en el caso del superior militar o autoridad y control, bien sea militares o no militares, debe ser efectivo sobre los subordinados.

3. Los actos cometidos por los subordinados se deben dar como resultado de un incumplimiento del superior de ejercer un control adecuado.

4. Falta del superior al no tomar las medidas necesarias y razonables.

5. Las medidas a adoptar deben estar encaminadas a prevenir o reprimir la comisión de crímenes o para poner el asunto en conocimiento de las autoridades competentes para la investigación y juzgamiento de los responsables.

En el punto quinto - destaca Ambos - hay una novedad en torno a las codificaciones anteriores, relacionada con la obligación del superior de poner en conocimiento de las autoridades competentes la comisión de los crímenes por parte de los subordinados.

Estos elementos objetivos han evolucionado a través de la jurisprudencia internacional y fueron codificados en el Estatuto de la Corte Penal Internacional. Ahora bien, en lo relativo al propósito doloso o mens rea, con relación a los jefes militares, el Estatuto establece que el superior "hubiere sabido o en razón de las circunstancias hubiere debido saber", con lo cual se recoge el conocimiento efectivo, el conocimiento constructivo, la ignorancia premeditada, la decisión premeditada de no conseguir información y la ignorancia negligente de la información disponible (Pérez- León Acevedo, 2007).

En aplicación del Estatuto de Roma se expidió la sentencia del caso Situation In The Central African Republic In The Case of The Prosecutor V Jean Pierre Bemba Gombo (2016). Esta sentencia está relacionada con la responsabilidad de un superior militar en el análisis que hiciera la sala sobre el control efectivo y la capacidad material para prevenir, o reprimir, la comisión de delitos; o someter el asunto a las autoridades competentes. Se estableció que los factores que pueden llegar a determinar estos supuestos son más de índole probatoria que de derecho sustantivo y pueden incluir:

1. La posición del comandante dentro de la estructura.

2. La facultad y capacidad para emitir órdenes a sus subordinados. 
3. La capacidad para asegurar el cumplimiento de las órdenes.

4. La capacidad de hacer cambios en la estructura de mando.

5. La facultad de remover o disciplinar a los miembros del grupo.

6. La capacidad de enviar y retirar fuerzas a los lugares donde se llevan a cabo las hostilidades.

7. Acceso y control sobre los medios para iniciar la guerra.

8. Control sobre las finanzas.

9. Capacidad de representar a las fuerzas en negociaciones.

10. Representación de la ideología del movimiento al cual adhieren los subordinados.

En esta misma sentencia se estableció que el control efectivo "es una manifestación de una relación jerárquica de iure o de facto", y que para determinar el control efectivo se debe establecer que el acusado "tenga poder material de prevenir o reprimir la comisión de crímenes o de someter el asunto a una autoridad competente", estableciendo además que el artículo 28 del Estatuto de Roma no exige que el superior "tenga única y exclusiva autoridad sobre las fuerzas que cometieron los crímenes" es decir "que múltiples superiores pueden cometer los crímenes" (Situation In The Central African Republic In The Case Of The Prosecutor V Jean Pierre Bemba Gombo, 2016).

Esta sentencia constituye el primer desarrollo jurisprudencial de la responsabilidad de los jefes y superiores por parte de la Corte Penal Internacional, que desarrolla con mayor énfasis los elementos objetivos que configuran esta responsabilidad con base en el control efectivo, por una parte. Y es que, de acuerdo con Olásolo, el control efectivo es la "piedra angular de toda relación superior-subordinado" y, de conformidad con el artículo 28 del Estatuto de Roma, "se refiere a la capacidad de evitar o reprimir la comisión de los delitos o, en su caso, de enviar la cuestión a las autoridades competentes" (2013: 29). No obstante, el mismo autor hace referencia a la jurisprudencia del Tribunal Penal Internacional para la ex Yugoslavia para dar el ejemplo de "la facultad de poner en conocimiento de las autoridades competentes la comisión de los delitos (sin importar si son fiscales militares $u$ ordinarios, o jueces de instrucción), podría ser suficiente para afirmar la existencia de un control efectivo" (Olásolo, 2013: 29).
Ahora bien, el requisito subjetivo (mens rea), se puede sintetizar así:

1. Que el militar o superior civil hubiera sabido que las fuerzas estaban cometiendo esos crímenes o se proponían cometerlos.

2. Que, en el caso de superiores militares, el comandante, en razón de las circunstancias del momento, hubiere debido saber que las fuerzas estaban cometiendo esos crímenes o se proponían cometerlos.

3. Que, en el caso de superiores civiles, el superior deliberadamente hubiere hecho caso omiso de información que indicase claramente que los subordinados estaban cometiendo esos crímenes o se proponían cometerlos.

\subsection{Responsabilidad de los Superiores No Militares}

En lo que tiene que ver con la responsabilidad de los superiores no militares, este fue un concepto que se empezó a desarrollar en los Tribunales Internacionales Penales de Nuremberg y Tokio, y que fue retomado en el caso Aleksovisk ante el TPIY (1999, p 15). Ahí se estableció que la responsabilidad "solamente se extiende a aquellos que ejercitan un grado de control sobre sus subordinados similar al de los comandantes militares"3.

Por su parte, en el Tribunal de Tokio, se estableció que

el miembro de un gabinete puede renunciar, si afirmativamente él tenía conocimiento de los malos tratos arrogados a los prisioneros, es impotente para impedir futuros maltratos, pero su elección es permanecer en el gabinete, entonces continúa participando en la responsabilidad colectiva (Brook, 2001: 102).

En este caso también ha sido el Tribunal de Tokio el que ha generado los antecedentes jurisprudenciales más estrictos en relación con la responsabilidad de los superiores no militares.

De otra parte, el artículo 28 del Estatuto de Roma establece, en el numeral B, la responsabilidad de los superiores no militares,

3. En el Tribunal de Nuremberg se había establecido la responsabilidad del superior que fuera "jefe, planificador o que hubiera pertenecido al nivel político". (Ambos, 1999). 
con tres elementos específicos: (i) el conocimiento real, (ii) el nexo de causalidad de "actividades bajo su responsabilidad", y (iii) la obligación de tomar las medidas necesarias para prevenir o reprimir la conducta (Olasolo \& Canosa, 2018).

En lo relativo a la responsabilidad de los superiores no militares, el mens rea se establece a partir de la premisa "hubiere tenido conocimiento o deliberadamente hubiere hecho caso omiso de información que indicase claramente que los subordinados estaban cometiendo esos crímenes o se proponían cometerlos" (Estatuto de la CPI, art. 28, parágrafo b.ii). En este caso se elimina el presupuesto de la ignorancia negligente de la información disponible $\mathrm{y}$, a su vez, esta disposición elimina para los superiores no militares lo relacionado al conocimiento en razón de las circunstancias.

Es claro que la responsabilidad para los superiores militares y no militares no puede ser tratada con los mismos criterios, toda vez que debe existir un control superior para quienes necesariamente hacen uso de la fuerza y de las armas.

En este orden de ideas, la responsabilidad de mando de los jefes y superiores, a partir del desarrollo del Derecho Internacional Penal, se configura desde un comportamiento omisivo por el incumplimiento de uno de los tres deberes prevenir, reprimir o castigar-. Lo anterior en razón a que el autor de la conducta no adoptó todas las medidas necesarias y razonables a su alcance para prevenir o reprimir la comisión del crimen, o no puso el asunto en conocimiento de las autoridades competentes a los efectos de su investigación y juzgamiento.

\section{RESPONSABILIDAD DE MANDO EN EL PROCESO DE JUSTICIA TRANSICIONAL EN COLOMBIA}

\subsection{Antecedentes de la Responsabilidad de Mando en Colombia}

El artículo 25 del Código Penal Colombiano (Ley 599, 2000) , establece que "la conducta punible puede ser realizada por acción o por omisión", y consagra además la teoría de la posición de garante que da lugar a la comisión por omisión. La aplicación de la comisión por omisión a los superiores militares ha sido justificada por la
Corte Constitucional Colombiana por encontrarse los mismos en una posición de garante frente al riesgo de afectar los bienes jurídicos de civiles, que es generado por: (i) la conducta de sus subordinados y (ii) la conducta de terceros (por ejemplo, miembros de la guerrilla o de grupos paramilitares) que actúan en su área de responsabilidad (Olasolo \& Canosa , 2018).

En 1999 se expidió la Ley 522 mediante la cual se expidió el Código Penal Militar, que derogaba el expedido en 1988 mediante decreto, en esta ley se estableció dentro de la modalidades de participación la figura del desistimiento de los partícipes por impedir la consumación de la conducta punible, exceptuando de responsabilidad a quien así actuara, este artículo fue revisado por la Corte Constitucional (Corte Constitucional, Sentencia C-368/2000, 2000) y declarado exequible en forma condicionada por la posible existencia de un delito "remanente" derivado del inicio de la conducta punible. A través de esta figura se pueden observar unos primeros visos en la legislación colombiana en el alcance de los deberes impuestos a los superiores con respecto a evitar la comisión de una conducta punible; en este caso se hizo a través de un beneficio de carácter punitivo, sin tomar en cuenta la posición jerárquica del autor de la conducta y trayendo además a consideración un pronunciamiento del mismo tribunal constitucional de 1997:

En un Estado de Derecho el poder punitivo tiene unos límites dados por el principio de proporcionalidad, en virtud del cual la graduación, en abstracto y en concreto, de la sanción, debe hacerse de acuerdo con la gravedad del injusto, y el grado de culpabilidad. Según el primer criterio, la intervención del derecho penal se dirige a sancionar las conductas lesivas de los bienes jurídicos que se estiman más valiosos, teniendo en cuenta que el hecho punible, además de lesionar bienes jurídicos particulares, atenta contra los valores ético-sociales predominantes en una sociedad determinada. El grado de culpabilidad, por su parte, involucra consideraciones acerca de la intencionalidad del hecho, esto es, de la conciencia y voluntad presentes en su realización, en virtud de los cuales se considera que la persona habría podido actuar de otra manera (Corte Constitucional, 1997).

En el año 2001, a través de la Sentencia de Unificación de Tutela SU 1184-01 de 2001, la 
Corte Constitucional se pronunció respecto a la posición de garante que tienen los miembros de la fuerza pública, en relación tanto a las conductas de acción, como las de omisión, en las que surge la responsabilidad de mando en el siguiente sentido:

En una teoría de la imputación objetiva construida sobre las posiciones de garante, predicable tanto de los delitos de acción como de omisión - la forma de realización externa de la conducta, es decir, determinar si un comportamiento fue realizado mediante un curso causal dañoso o mediante la abstención de una acción salvadora, pierde toda relevancia porque lo importante no es la configuración fáctica del hecho, sino la demostración de sí una persona ha cumplido con los deberes que surgen de su posición de garante. Si alguien tiene deberes de seguridad en el tráfico, lo trascendente para la imputación es si esa persona desplegó deberes de diligencia para evitar que el peligro creado no excediera los límites de lo prohibido. Si se es garante, no interesa si el sujeto originó un curso causal (acción) o no impidió el desarrollo del mismo (omisión), sino, si ha cumplido con los deberes de seguridad que le impone el ejercicio de una actividad peligrosa. (Corte Constitucional, 2001: 35).

Este antecedente jurisprudencial constituye un importante precedente frente a los elementos objetivos que constituyen la responsabilidad de mando, a través de un análisis de las actividades de riesgo, como lo es el uso legítimo de las armas del Estado. Este antecedente, de manera irreductible, impone a quienes ejercen un mando al interior de la fuerza pública ejercer un control adecuado sobre sus subordinados, so pena de incurrir en algún tipo de responsabilidad, no derivado de la acción, sino de la omisión que permite que no se eviten o no cesen las conductas delictivas.

En desarrollo del concepto de la comisión por omisión se han sancionado conductas que constituyen graves violaciones a los derechos humanos, así como graves infracciones al Derecho Internacional Humanitario. Es así como, en el año 2014, la Corte Suprema de Justicia, mediante Sentencia SP 7135 de 2014, encontró penalmente responsable a un miembro de la Fuerza Pública, que no cumplió con los deberes que le imponía su posición de garante, bajo la consideración de que:
En una grave violación a los derechos fundamentales, la conducta del garante que interviene activamente en la toma de una población, es similar a la de aquel que no presta la seguridad para que los habitantes queden en una absoluta indefensión. En virtud del principio de igualdad, cuando la acción y la omisión son estructural y axiológicamente idénticas, las consecuencias deben ser análogas: Si la conducta activa es ajena al servicio, también deberá serlo el comportamiento omisivo. Un miembro de la fuerza pública puede ser garante cuando se presenten cualquiera de los dos fundamentos de la responsabilidad explicados: creación de riesgos para bienes jurídicos o surgimiento de deberes por la vinculación a una institución estatal. Las fuerzas militares tienen la obligación absoluta de impedir el desconocimiento del derecho internacional humanitario (restricción absoluta aun frente a los estados de excepción según lo dispone el artículo 214 de la Constitución) y los derechos que, conforme a los tratados internacionales ratificados por Colombia, no pueden ser suspendidos durante tales estados (Corte Suprema de Justicia, 2014: 17).

Ahora bien, otro de los conceptos relacionados con la responsabilidad de mando y del superior es la denominada teoría de los aparatos organizados de poder. En este sentido la Corte Suprema de Justicia, en relación con la tesis de la Autoría Mediata, estableció que para que se configure la responsabilidad de mando, se requiere la expedición de órdenes específicas, que van decendiendo en una cadena jerárquica, hasta llegar al autor material del hecho. Así las cosas, los primeros en la "piramide" son los autores mediatos, constituidos por los mandos altos y medios; y los gestores de la acción son los coautores (Corte Suprema de Justicia, 2014).

$\mathrm{Al}$ respecto refiere Cadavid (2013) que, desde una perspectiva dogmática, para calificar la intervención del superior en Aparatos Organizados de Poder, se usa la coautoría en virtud de la organización, debido a que esta modalidad es la que recoge de mejor manera la forma de realización de conductas delictivas en el marco de estas estructuras delincuenciales. Si bien es cierto en los Aparatos Organizados de Poder de Carácter delincuencial se pueden aplicar todas las formas de participación en la conducta penal, por la posición que ocupa el superior, como lo refiere la misma autora, tiene el dominio del hecho. 
Siguiendo esta línea interpretativa de la responsabilidad del superior, a partir de la autoría mediata, refiere (Roxin, 1998) al analizar la figura del "instrumento", que este va más allá del denominado "hombre de atrás" y hace referencia al aparato como tal. Aunque en este tipo de responsabilidad se pueden enmarcar algunos casos de responsabilidad del superior, cuando la conducta no es de carácter omisivo, no es suficiente para definir con certeza los casos en que puede aplicarse la responsabilidad del superior, como una categoría de imputación.

Sólo a partir del desarrollo constitucional y legal del Acuerdo Final para la Terminación del Conflicto y la Construcción de una Paz Estable y Duradera (En adelante Acuerdo Final) es que se está consagrando por primera vez, de forma expresa, en la legislación colombiana la responsabilidad de mando y del superior, bajo el concepto que establece el Derecho Penal Internacional y el Derecho Internacional Humantario, aunque con serias diferencias, como se podrá verificar en los siguientes apartados.

\subsection{Responsabilidad de Mando en el Acuerdo Final de Paz en Colombia}

Teniendo en cuenta el marco general regulatorio de la responsabilidad de mando en el Derecho Penal Internacional, se hará un análisis del manejo de la responsabilidad de mando en el Acuerdo Final (2016), suscrito entre el Gobierno Nacional y las Fuerzas Armadas Revolucionarias de Colombia - FARC-EP.

El 24 de agosto de 2016 se terminó de redactar el primer Acuerdo Final que fue suscrito en la ciudad de Cartagena el 26 de septiembre de 2016. En este Acuerdo -en los numerales 44 y 59 del punto $5^{\circ}$, sobre las víctimas del conflicto, en el capítulo de la Jurisdicción Especial de Paz- se estableció la responsabilidad de mando de los miembros de la fuerza pública y de los integrantes de las FARC-EP, respectivamente. Nada se dijo de la responsabilidad de los superiores civiles.

En torno a la responsabilidad de los miembros de la fuerza pública, se estableció que, para que se configure la responsabilidad del superior, debe existir un control efectivo de la respectiva conducta y no de los subordinados. Frente al elemento subjetivo, se estableció el conocimiento basado en la información a su disposición antes, durante y después de la realización de la conducta; y, por último, en relación con el deber de diligencia, se estableció el deber de tomar las medidas a disposición de los superiores para prevenir los delitos y promover las investigaciones una vez cometidos los mismos.

En lo que tiene que ver con la responsabilidad de mando de los miembros de las FARC -EP, se establecieron los mismos elementos de control efectivo sobre la conducta: la información a su disposición antes, durante y después de la realización de la conducta; el deber de prevenir y de adoptar las decisiones correspondientes en caso de que la conducta hubiere sido cometida.

Estas dos disposiciones consagraban diferencias significativas en relación con lo establecido sobre responsabilidad de mando en el Estatuto de la Corte Penal Internacional. Por una parte, establecían un control sobre la conducta y no sobre los subordinados; y por otra establecían, además, de forma exclusiva, el conocimiento efectivo; debe resaltarse que se omitió el deber de represión de la conducta.

Luego de que fuera sometido a refrendación popular mediante plebiscito, y de que la ciudanía tomara una decisión negativa respecto al mismo, este acuerdo fue objeto de renegociación, esta vez incluyendo a los principales actores políticos que lideraron la campaña del voto por el NO, en este mecanismo de participación democrática (Gómez, 2017).

Luego de esta renegociación, el 23 de noviembre de 2016 se hizo público el nuevo Acuerdo Final, y los numerales 44 y 59 tuvieron sus respectivas modificaciones. Al numeral 44 , relacionado con la responsabilidad de los miembros de la fuerza pública, se le adicionó un párrafo en el que se establecía el deber de control del superior sobre los subordinados, y se hacía referencia expresa al artículo 28 del Estatuto de Roma, con los elementos precisos que este artículo contiene en relación con los componentes definitorios de la responsabilidad de mando ${ }^{4}$. En

4. En este numeral 44 del Acuerdo se adicionó el siguiente párrafo: "Se entiende por control efectivo de la respectiva conducta, la posibilidad real que el superior tenía de haber ejercido un control apropiado sobre sus subalternos, en relación con la ejecución de la conducta delictiva, tal y como lo indica el artículo 28 del Estatuto de Roma". 
el numeral 59, relativo a la responsabilidad de los miembros de las FARC EP, se hizo una precisión similar, haciendo también la referencia al artículo 28 del Estatuto de la $\mathrm{CPI}^{5}$.

Si bien se dio este importante avance de estos nuevos párrafos -incluidos el 12 de noviembre de $2016^{6}$ (Paz, 2016), cuando se terminó de redactar la renegociación del Acuerdo en la ciudad de La Habana, y que aparecieron en la publicación oficial del 23 de noviembre- en el caso del numeral 44, el párrafo adicionado fue eliminado en una nueva publicación del 24 de noviembre en una versión final que fue suscrita por los negociadores de ambas partes, conservando la redacción original del texto de agosto.

En el numeral 59, relacionado con la responsabilidad de mando de los miembros de las FARC -EP, aunque se mantuvo parte del párrafo que se adicionó posteriormente, se cambió la remisión al artículo 28 del Estatuto de Roma por una remisión al derecho internacional en los siguientes términos:

Se entiende por control efectivo de la respectiva conducta, la posibilidad real que el superior tenía de haber ejercido un control apropiado sobre sus subalternos, en relación con la ejecución de la conducta delictiva, tal y como se establece en el derecho internacional (Acuerdo Final, 2016:164).

Ahora bien, el control efectivo - como se estableció para los miembros de la Fuerza Pública en el acuerdo final, referido a la conducta y no al autor de esta - representa una grave ambigüedad que limita los casos de responsabilidad de mando que pudieron haber ocurrido durante el conflicto armado colombiano. Adicional a esto, tanto para los miembros de la Fuerza Pública como para los miembros de las FARC-EP, se estableció la responsabilidad sólo sobre el conocimiento efectivo, sin tomar en cuenta el conocimiento relacionado con la expresión "tenía razones para saber" del artículo 28 del Estatuto de Roma, cuya referencia fue eliminada en relación con la

5. El mismo párrafo final del numeral 44, aparecía en el numeral 59, referido a la Responsabilidad de Mando de los miembros de las FARC-EP.

6. Documento de trabajo: Cambios precisiones y ajustes para un nuevo Acuerdo Final para la Terminación del Conflicto y la Construcción de una Paz Estable y Duradera. Oficina del Alto Comisionado para la Paz, 11 de noviembre de 2016. responsabilidad de mando, tanto de los miembros de la Fuerza Pública, como de las FARC.

Las disposiciones del punto 5o del Acuerdo Final relacionado con las víctimas del conflicto se hicieron públicas en el mes de diciembre del año 2015. Dentro de las críticas que desató la regulación de la responsabilidad de mando cabe destacar las de la ONG Human Rights Watch, HRW, (2015), en documento remitido al presidente de la República, en el que se estableció que los apartes regulatorios de la responsabilidad de mando contenían dos frases ambiguas que daban un amplio margen de interpretación para la determinación de la responsabilidad de los superiores miembros de la Fuerza Pública y de las FARC.

La primera frase considerada ambigua es la relacionada con la información disponible antes, durante y después de la comisión de la conducta, toda vez que el derecho internacional basa el elemento subjetivo en las expresiones "debería haber sabido o tenía razones para saber". La segunda frase es la relacionada con el control efectivo sobre la conducta. De acuerdo con la ONG arriba mencionada, en el derecho internacional el control que debe ejercer el superior es sobre sus subordinados y no "específicamente sobre el hecho ilícito".

Luego de la firma del Acuerdo de Paz el 24 de noviembre de 2016, HRW (2017) volvió a pronunciarse en torno a la responsabilidad de mando y su regulación en el Acuerdo, estableciendo su preocupación por la eliminación de las nuevas disposiciones sobre responsabilidad de mando para los agentes del Estado, horas antes de la firma del nuevo Acuerdo.

\subsection{Acto Legislativo 01 de 2017}

Posteriormente, como parte del desarrollo constitucional del Acuerdo Final, en el mes de abril de 2017 se expidió el Acto Legislativo 01. En el artículo $24^{7}$ de esta reforma constitucional, se

\section{Acto Legislativo 01 de 2017:}

(...)

Artículo transitorio $24^{\circ}$. Responsabilidad del mando. Para la determinación de la responsabilidad del mando, la Jurisdicción Especial para la Paz aplicará, en el caso de los miembros de la Fuerza Pública, el Código Penal colombiano, el Derecho Internacional Humanitario como ley especial, y las reglas operacionales de la Fuerza Pública en relación con el DIH siempre que ellas no sean contrarias a la normatividad legal. La determinación de la responsabilidad del mando no podrá fundarse exclusivamente en el rango, la jerarquía o el ámbito de 
definieron los principios de la responsabilidad de mando para los miembros de la Fuerza Pública, estableciendo cuatro condiciones concurrentes que deben ser demostradas para que se configure este tipo de responsabilidad.

Estas cuatro condiciones exigen que la conducta se haya cometido dentro del área de responsabilidad del superior, que el superior tenga capacidad tanto legal como material para expedir órdenes, que el superior tenga la capacidad efectiva de desarrollar y ejecutar operaciones dentro del área donde se cometieron los hechos, además de la capacidad material del superior para evitar o reprimir la conducta.

En esta reforma constitucional no se fijaron los principios de responsabilidad de mando para los miembros de las FARC, y la regulación que se hizo para los miembros de la Fuerza Pública no sólo presenta ambigüedades, sino que ahora presenta unas exigencias exhaustivas, consagradas en la Constitución Política; lo que genera mayores dificultades para establecer la responsabilidad de los mandos militares y policiales por los crímenes de sus subalternos (Olásolo y Canosa, 2018).

En el caso de la responsabilidad de mando de los militares, en la disposición constitucional se estableció que, para definir el mando y control efectivo, debe probarse la existencia de los siguientes cuatro elementos concurrentes.

El primero exige que la conducta haya sido cometida dentro del área de responsabilidad

jurisdicción. La responsabilidad de los miembros de la Fuerza Pública por los actos de sus subordinados deberá fundarse en el control efectivo de la respectiva conducta, en el conocimiento basado en la información a su disposición antes, durante, o después de la realización de la respectiva conducta, así como en los medios a su alcance para prevenir que se cometa o se siga cometiendo la conducta punible, siempre y cuando las condiciones fácticas lo permitan, y de haber ocurrido, promover las investigaciones procedentes.

Se entenderá que existe mando y control efectivo del superior militar o policial sobre los actos de sus subordinados, cuando se demuestren las siguientes condiciones concurrentes:

a. Que la conducta o las conductas punibles hayan sido cometidas dentro del área de responsabilidad asignada a la unidad bajo su mando según el nivel correspondiente y que tengan relación con actividades bajo su responsabilidad;

b. Que el superior tenga la capacidad legal y material de emitir órdenes, de modificarlas o de hacerlas cumplir;

c. Que el superior tenga la capacidad efectiva de desarrollary ejecutar operaciones dentro del área donde se cometieron los hechos punibles, conforme al nivel de mando correspondiente; y directa de tomar las medidas adecuadas para evitar o reprimir la conducta o las conductas punibles de sus subordinados, siempre y cuando haya de su parte conocimiento actual o actualizable de su comisión. asignada bajo su mando. En este sentido, en la Sentencia del caso Situation In The Central African Republic In The Case of The Prosecutor V Jean Pierre Bemba Gombo (2016,), se estableció:

(...) el hecho de que las tropas del señor Bemba se comunicaron y cooperaron con las autoridades de la República Centroafricana a lo largo de la operación, no significa que el Sr. Bemba careciera de autoridad y control efectivo sobre estas tropas, a pesar de que ellas operaran en territorio extranjero (pág. 245).

Es así como - de acuerdo con la teoría del control efectivo, como se verá a continuaciónno resulta pertinente exigir que la conducta se cometa dentro del área de jurisdicción del responsable, toda vez que el control sobre las tropas es independiente de donde estas operen; y va más encaminado a la capacidad de emitir y hacer cumplir estas órdenes y a su vez a la capacidad de poder evitar las conductas delictivas que los inferiores pretenden realizar.

El segundo elemento es tener la capacidad legal y material de emitir órdenes, modificarlas y hacerlas cumplir. Esta disposición está relacionada con el control efectivo, que, como se analizó anteriormente, la regulación constitucional que se hizo lo relaciona con el control sobre la conducta y no sobre sus subordinados. Al respecto, en Prosecutor v. Martic se mencionó frente al control efectivo:

El Tribunal tiene razones válidas particulares para ejercer su jurisdicción sobre personas que, por su posición de autoridad política o militar, pueden ordenar la comisión de crímenes dentro de su competencia ratione materiae o que pese a conocer de dicha comisión se abstengan de prevenir o castigar a los perpetuadores de tales crímenes (Prosecutor v. Martic, 1996).

En el mismo sentido, en la Sentencia del Caso Bemba se estableció que

(...) la posesión de poder formal no es un factor determinante para demostrar la existencia de un control efectivo de acuerdo con el artículo 28 del Estatuto de Roma, el control efectivo puede establecerse dentro de una relación jerárquica de iure o de facto. (Situation In The Central African Republic In The Case of The Prosecutor V Jean Pierre Bemba Gombo, 2016, : 248) 
Exigir un control efectivo sobre la conducta y no sobre los subordinados modifica estos principios establecidos por la jurisprudencia y lleva la responsabilidad de mando a un control real y material sobre cada conducta cometida.

Un tercer elemento es exigir la capacidad efectiva de desarrollar y ejecutar operaciones dentro del área donde se cometieron los hechos punibles, estableciendo, además, que sea conforme al nivel de mando correspondiente. En este sentido, la sala de primera instancia de la CPI fundamentó la diferencia entre el concepto de unidad de mando y control efectivo,

(...) estableciendo con respecto a la unidad de mando, que para el buen funcionamiento de un ejército, solo puede haber un individuo en mando de una unidad específica y en un momento en particular, no obstante el poder material para prevenir, reprimir o someter la conducta delictiva a las autoridades competentes no puede ser un poder exclusivo y múltiples superiores pueden ser conjuntamente responsables de las acciones de sus subordinados (Situation in the Central African Republic in the Case of The Prosecutor V Jean Pierre Bemba Gombo, 2016: 315).

En este punto se entra nuevamente en la discusión de si el control territorial es o no definitorio de la responsabilidad de mando. Como se puede verificar en los dos apartes de la sentencia del caso Bemba, la conclusión a la que llegó la CPI es que no debe existir ese control para que se pueda configurar la responsabilidad.

El cuarto y último elemento concurrente exigido es la capacidad material y directa de tomar las medidas adecuadas para evitar o reprimir la conducta o las conductas punibles de sus subordinados, requiriéndose además un conocimiento actual o actualizable.

En este sentido, establecer exclusivamente el conocimiento real en relación con la responsabilidad de mando permite justificar conductas negligentes que generan una omisión; con lo cual se limita en forma desproporcional la responsabilidad que deben tener los jefes y superiores frente a la comisión de delitos de competencia de la CPI.
Estas disposiciones suscitaron pronunciamientos de importantes organizaciones de la sociedad civil en Colombia, tales como DeJusticia y la Comisión Colombiana de Juristas ${ }^{8}$. En el caso de DeJusticia, la sugerencia fue establecer que esas condiciones constituyen criterios de interpretación para los jueces de la Jurisdicción Especial de Paz, tomando en cuenta, además, que serán estos jueces los que en cada caso determinarán, con base en los elementos que constituyen la responsabilidad de mando, si esta efectivamente se dio o no.

Por su parte, la Comisión Colombiana de Juristas recordó cómo la omisión de las referencias al derecho internacional, no omite la aplicación de los conceptos que establece el Derecho Internacional de los Derechos Humanos o el Derecho Internacional Penal. Por tal razón, haber omitido la referencia al artículo 28 del Estatuto de Roma, o al derecho internacional en general, no lo hace inaplicable para los actores del conflicto armado colombiano? .

En este sentido la Corte Constitucional estableció en la Sentencia C-084 de 2016 la debida armonización que debe existir entre el derecho interno y las normas del derecho internacional de los derechos humanos, así como el Derecho Internacional Humanitario, en los siguientes términos:

Este entendimiento de la norma reformatoria de la Constitución no sustituye, ni subvierte el deber del Estado de respetar, hacer respetar, garantizar y proteger los derechos humanos, mediante la investigación y juzgamiento de las graves violaciones a los derechos humanos y las graves infracciones al derecho internacional humanitario. Por el contrario, su interpretación armónica con los principios $\mathrm{y}$ valores que orientan el modelo de Estado social y democrático de derecho y los demás preceptos constitucionales y del bloque de constitucionalidad, reafirma, desarrolla $y$ contribuye a la realización del eje definitorio identificado como parámetro del control en el presente juicio (Corte Constitucional, 2016).

8. Audiencia Pública Proyecto de Acto Legislativo 02 de 2017 Senado/002 de 2016 Cámara, 14 de febrero de 2017.

9. Audiencia Pública Proyecto de Acto Legislativo 02 de 2017 Senado/002 de 2016 Cámara, 14 de febrero de 2017. 
Desde la teoría jurídica no hay duda de que las disposiciones del Estatuto de Roma hacen parte del Ius Cogens, siguiendo la misma línea interpretativa planteada por la Corte Constitucional desde 1995, determinando que este tipo de normas

buscan, ante todo, proteger la dignidad de la persona humana. Son pues normatividades complementarias que, bajo la idea común de la protección de principios de humanidad, hacen parte de un mismo género: el régimen internacional de protección de los derechos de la persona humana. La diferencia es entonces de aplicabilidad, puesto que los unos están diseñados, en lo esencial, para situaciones de paz, mientras que los otros operan en situaciones de conflicto armado (Corte Constitucional, 1995).

$\mathrm{Y}$ es que, en efecto, el Estatuto de Roma no fue sólo ratificado en Colombia mediante la Ley 742 de 2002 sino que, además, mediante la reforma constitucional del Acto Legislativo 02 de 2001, se reconoció la jurisdicción de la Corte Penal Internacional, estableciendo la posibilidad de que existan diferencias entre las garantías constitucionales y lo previsto en el Estatuto de Roma, como por ejemplo en lo relativo a la pena de prisión perpetua, en virtud el concepto de "tratamiento diferenciado", que hace que las normas recogidas en el Estatuto de Roma que no se ajustan a las garantías constitucionales sean solamente aplicables en los procedimientos ante la Corte Penal Internacional.

En este sentido, en el año 2012, la Fiscalía de la Corte Penal Internacional presentó un reporte intermedio sobre la Situación en Colombia (Fiscalía de la CPI, 2012). En ese informe se examinaron los efectos violentos del conflicto sobre las personas y, bajo un análisis de complementariedad, se estableció que - frente a los actores del conflicto que hacían parte en su época de la guerrilla de las FARC-EP, que hacen parte de la guerrilla del ELN y que hicieron parte de los grupos paramilitares - el Estado ha cumplido con el deber de investigar y sancionar las conductas cometidas por los miembros de estos grupos, por lo que no sería admisible una denuncia en contra de estos ante la CPI.

Sin embargo, en lo que tiene que ver con agentes del Estado - no sólo respecto a miembros de la Fuerza Pública - la Fiscalía de la CPI detectó deficiencias relacionadas con "ciertas categorías de personas y crímenes"10.

Tomando en cuenta el informe de la Fiscalía de la CPI, se tornan de especial importancia los aspectos definitorios de la responsabilidad de mando para los miembros de la Fuerza Pública, partiendo de la base de las deficiencias en la aplicación de justicia para algunos funcionarios públicos, no solo miembros de la Fuerza Pública, cuyos procesos judiciales no se han adelantado en forma adecuada, situación que ya fue percibida por la CPI.

Ya en el año 2016, la Fiscalía presentó un Informe sobre las Actividades de Examen Preliminar, en el que estableció:

La Fiscalía también deberá tomar en consideración si existe alguna laguna sustantiva en las leyes aplicadas por las autoridades competentes de la jurisdicción especial para la paz, como las relativas a la responsabilidad del superior, que podría socavar su capacidad de proceder de manera genuina en relación con los casos potenciales que podrán surgir de una investigación en la situación (Corte Penal Internacional, 2016).

Estas lagunas sustantivas, a las que hace referencia la Fiscalía, vienen desde la redacción de la responsabilidad de mando del Acuerdo Final y persisten en la regulación e implementación constitucional y legal que se está haciendo del Acuerdo. A pesar de este importante antecedente, la Corte Constitucional, en sentencia C-614 de 2017, se pronunció sobre la constitucionalidad del Acto Legislativo 01 de 2017. A través de esta sentencia se hicieron ajustes a siete artículos del acto legislativo, pero no hubo ninguna modulación al artículo $24^{\circ}$, relacionado con la responsabilidad

10. En el Reporte Intermedio de 2012, se llegó a las siguientes conclusiones:

199. Por lo que se refiere a otros agentes, la Fiscalía ha detectado ciertas carencias o deficiencias que indican una actividad insuficiente o incompleta con respecto a ciertas categorías de personas y de crímenes. En particular, y como lo han señalado las propias autoridades colombianas, es necesario establecer mejor las prioridades.

200. En la evaluación de admisibilidad, la Fiscalía ha evaluado si los posibles casos que investigaría son o serían inadmisibles, debido a la existencia de actuaciones nacionales pertinentes. No obstante, todo ello es sin perjuicio del deber más amplio de los Estados de ejercer su jurisdicción penal sobre los responsables de crímenes internacionales. Por lo tanto, la priorización de casos para determinar la admisibilidad ante la CPI no debe conllevar impunidad por otros crímenes. 
de mano de los miembros de la Fuerza Pública, a pesar de las diferentes observaciones remitidas a la Corte, frente a esta materia.

(...) con base en su reconocimiento progresivo en el siglo XX, el CICR concluyó en 2005 que el principio de responsabilidad del superior tenía sin menor duda el rango de norma del Derecho Internacional Humanitario consuetudinario, en los siguientes términos: "los jefes y otros mandos superiores son penalmente responsables de los crímenes de guerra cometidos por sus subordinados si sabían, o deberían haber sabido, que estos iban a cometer o estaban cometiendo tales crímenes y no tomaron todas las medidas razonables y necesarias a su alcance para evitar que se cometieran o, si se habían cometido, para castigar a los responsables (CICR, 2017).

Llama la atención que a pesar de que el Estado colombiano ha sido advertido en los informes de examen preliminar, sobre las dudas que hay en torno a las investigaciones judiciales de los agentes del Estado que han incurrido en responsabilidad en relación con los crímenes de competencia de la CPI, desde el Acuerdo Final se ha mantenido una regulación incompleta frente a los elementos mínimos que de conformidad con el derecho internacional de los derechos humanos y el derecho internacional penal debe contener la responsabilidad de mando (Olasolo \& Canosa , 2018).

La Corte Constitucional, en sentencia C-614 de $2017^{11}$, se pronunció sobre la constitucionalidad del Acto Legislativo 01 de 2017. A través de esta sentencia se hicieron ajustes a siete artículos del acto legislativo, pero no hubo ninguna modulación al artículo $24^{\circ}$ relacionado con la responsabilidad de mando de los miembros de la Fuerza Pública, a pesar de las diferentes observaciones remitidas a la Corte, frente a esta materia.

\subsection{Ley Estatutaria de la Jurisdicción Especial de Paz}

Luego de la expedición del Acto Legislativo que incorporó en la Constitución Política la Jurisdicción Especial de Paz, fue radicado, en el mes de agosto del año 2017, el Proyecto de Ley Estatutaria de la Administración de Justicia

11. Comunicado de Prensa Corte Constitucional 14 de noviembre de 2017. en la Jurisdicción Especial para la Paz (Senado, 2017). En este proyecto de ley se desarrolla en el artículo $67^{12}$ finalmente aprobado, el concepto de responsabilidad de mando de los miembros de las FARC-EP. También se transcribe parte del numeral 59 del Acuerdo de Paz manteniendo, entre otros, la teoría del control efectivo sobre la respectiva conducta, aun cuando en el segundo párrafo se hace referencia al control efectivo sobre los subalternos que cometen la conducta. Continúa además la aplicación de la teoría del conocimiento efectivo, omitiendo lo relativo al conocimiento constructivo.

Con relación a la responsabilidad de mando de los militares, se menciona, en el artículo 68 del proyecto de ley aprobado, una remisión expresa al contenido del artículo 24 del Acto Legislativo 01 de 2017. No obstante las falencias de este artículo en cuanto al contenido y elementos de la responsabilidad definidos por el Derecho Penal Internacional de mando frente a miembros retirados de la Fuerza Pública, se solicitó mediante carta dirigida al presidente del Congreso de la República, el 16 de agosto de 2017, la adición del artículo sobre responsabilidad de mando que remite a la reforma constitucional para que se consagre la frase: "en materia penal prima el derecho interno tanto en la parte sustantiva como procedimental y no el de carácter internacional".

Esta disposición que solicitan los miembros de la reserva activa de la Fuerza Pública - como se determinó anteriormente- al pretender excluir el derecho internacional de la normatividad interna en el proceso de juzgamiento de los más graves delitos, no representa un blindaje suficiente para que la CPI considere que existieron los mínimos de justicia exigidos que eviten que se aplique su jurisdicción complementaria y en efecto la mencionada disposición no fue incluida.
12. ARTÍCULO 67. RESPONSABILIDAD DE LOS MANDOS DE LAS FARC-EP. La responsabilidad de los mandos de las Farc-EP por los actos de sus subordinados deberá fundarse en el control efectivo de la respectiva conducta, en el conocimiento basado en la información a su disposición antes, durante y después de la realización de la respectiva conducta, así como en los medios a su alcance para prevenirla, y de haber ocurrido adoptar las decisiones correspondientes. La responsabilidad del mando no podrá fundarse exclusivamente en el rango o la jerarquía. Se entiende por control efectivo de la respectiva conducta la posibilidad real que el superior tenía de haber ejercido un control apropiado sobre sus subalternos, en relación con la ejecución de la conducta delictiva, tal y como se establece en el derecho internacional. 
En el artículo 61 de la Ley Estatutaria, que regula la administración de justicia de la Jurisdicción Especial de Paz, la responsabilidad de mando de los miembros de las FARC-EP quedó definida en estos términos, con los siguientes elementos:

1. Se exige un control efectivo sobre la conducta y no sobre los subordinados.

2. Se establece la existencia del conocimiento efectivo, sin tomar en cuenta el conocimiento constructivo, derivado de la conocida expresión "tenía razones para saber".

3. Solo se establece el deber de prevención y de forma ambigua el deber de represión de la conducta, al consagrar la expresión "y de haber ocurrido adoptar las decisiones correspondientes".

4. Frente al control efectivo, se establece "la posibilidad real que el superior tenía de haber ejercido un control apropiado sobre sus subalternos, en relación con la ejecución de la conducta delictiva, tal y como se establece en el derecho internacional".

Frente a este último punto, es claro que la responsabilidad de mando, tal y como ha sido definida en el Derecho Internacional Penal, no está ligada de forma exclusiva a la existencia de un rango o jerarquía; sino a la posibilidad real del superior de ejercer un control sobre sus subordinados, tomando en cuenta además lo establecido en el caso. "Ha sido sometido a consideración que la responsabilidad criminal del superior dependerá del grado y forma de control que ejercite y los medios a su disposición para controlar a sus subordinados" (Mucić et al., 1996: 28).

Frente a los demás elementos constitutivos de la responsabilidad de mando de los miembros de las FARC-EP, es claro que existen también deficiencias frente a la construcción de los elementos y el avance de este tipo de responsabilidad en el Derecho Internacional Penal, al establecer un deber de control sobre la conducta y no sobre los subordinados, con lo cual se limita la teoría del control efectivo y se encamina la regulación a la forma más básica de comisión por omisión.

Frente al conocimiento, también se establece su forma más primigenia, relacionada con el conocimiento real, sin tomar en cuenta ninguna de las otras formas de conocimiento, omitiendo además lo establecido en el artículo 28 del
Estatuto de Roma bajo la expresión "tenía razones para saber".

En lo relativo al deber de prevención, represión y denuncia, tampoco se está dando la suficiente claridad frente a los aspectos que se deben cumplir al respecto. Al hacer mención simplemente a las "decisiones correspondientes", se está dando un amplio margen de interpretación frente al contenido material exigido a este tipo de decisiones.

El artículo 28 del Estatuto de Roma consagra la obligación de adoptar las medidas "necesarias y razonables", para cumplir con los deberes anteriormente mencionados. Estos dos conceptos se relacionan con las medidas "adecuadas para que el comandante cumpla las obligaciones deducidas de su posición". Al respecto, en la sentencia del caso Situation In The Central African Republic In The Case Of The Prosecutor V Jean Pierre Bemba Gombo, estableció la sala:

El deber del comandante de tomar todas las medidas necesarias y razonables para prevenir o reprimir los crímenes cometidos por sus subalternos, o para poner el asunto en conocimiento de las autoridades competentes para la investigación y el enjuiciamiento de conductas y presuntos autores, se apoya en su posición de autoridad efectiva y de control sobre los actos de sus subordinados. No es determinante que el comandante tenga la "capacidad jurídica explícita" de tomar esas medidas; lo que importa es su capacidad material para llevar a cabo tales actos. En otras palabras, lo que constituye el estándar de "todas las medidas razonables y necesarias dentro de su alcance" se evaluará sobre la base del mandato de jure y/o poder de facto del comandante y el ejercicio real que él o ella hace de este poder. En este escenario el alcance probatorio que tiene el derecho operacional es fundamental (2016: 15).

En este orden de ideas, si bien es cierto que la CPI ha definido que la verificación de si se cumplieron las medidas necesarias y razonables se debe hacer caso por caso, también lo es que al hablar de "decisiones correspondientes", no se está imponiendo un deber jurídico claro que pueda ser determinable con precisión.

Finalmente, la referencia al derecho internacional, se está haciendo ligada a lo 
preceptuado en el artículo, sin hacer una remisión expresa a disposiciones normativas específicas, en especial el artículo 28 del Estatuto de Roma.

\subsection{Otras Disposiciones Pendientes}

Adicional a lo anterior, ni en el Acuerdo Final ni en la regulación constitucional y legal se estableció el concepto de responsabilidad de mando de los superiores no militares, toda vez que está claramente establecido que no sólo los miembros de la Fuerza Pública y los grupos insurgentes fueron los autores de los más graves delitos cometidos en el marco del conflicto armado colombiano.

En el caso de la responsabilidad de civiles no militares el CICR (2012) ha establecido que un superior jerárquico que mantiene con sus subordinados una relación distinta de la militar, es penalmente responsable de los crímenes que son de la competencia de la Corte, y que hubieren sido cometidos por subordinados bajo su autoridad y su control efectivo, bajo los presupuestos establecidos en el Estatuto de la CPI.

No obstante esta interpretación, de conformidad con el Acto Legislativo 01 de 2017, los civiles, no militares, tendrán un tratamiento de terceros, con participaron en forma indirecta del conflicto armado colombiano, que pueden acudir a la Jurisdicción Especial de Paz, en forma exclusivamente voluntaria, razón por la cual la responsabilidad del superior no tendrá cabida en relación a las conductas cometidas por estos, aun cuando se trate de actores estatales que pudieron evitar o hacer cesar la comisión de conductas de competencia de la CPI.

En este orden de ideas, la inclusión al ordenamiento jurídico colombiano de la responsabilidad de mando y del superior se está limitando a la existencia de unos elementos definitorios concurrentes, si bien también hay unas claras diferencias sustanciales con el desarrollo jurisprudencial que se ha dado en el Derecho Penal Internacional, en el marco de investigaciones de los más graves crímenes internacionales. Se omite además la responsabilidad de los civiles no militares, cuando "claramente se ha podido establecer que en Colombia hubo una participación activa de civiles en el conflicto" (CICR, 2017: 7), que fue determinante en la comisión de graves conductas que constituyen delitos de lesa humanidad y graves crímenes de guerra, de competencia de la CPI (Olásolo y Canosa, 2018) ${ }^{13}$.

Es fundamental, por último, recordar que el artículo 20 del Estatuto de Roma establece, en relación con la cosa juzgada, que la Corte no procesará a nadie que haya sido procesado por otro tribunal, a menos que:

(...) b) No hubiere sido instruida en forma independiente o imparcial de conformidad con las debidas garantías procesales reconocidas por el derecho internacional o lo hubiere sido de alguna manera que, en las circunstancias del caso, fuere incompatible con la intención de someter a la persona a la acción de la justicia. (Estatuto De La Corte Penal Internacional, 1998)

En este orden de ideas, tratar de generar un blindaje jurídico que limite al máximo la responsabilidad de mando - tal y como se ha venido haciendo desde el Acuerdo Final, hasta su implementación constitucional y ahora legalno significa que la CPI no pueda, con base en el principio de complementariedad, avocar el conocimiento de esas conductas cuando no se garantice el cumplimiento de las actuaciones judiciales pertinentes.

\section{CONCLUSIONES}

A través del desarrollo constitucional y legal de las disposiciones del Acuerdo Final para la Terminación del Conflicto y la construcción de una Paz Estable y Duradera, se está incorporando por primera vez al ordenamiento jurídico colombiano la figura del derecho penal internacional de la responsabilidad de mando o del superior. La referencia legal más cercana a esta figura ha sido la comisión por omisión, consagrada en el Código Penal colombiano.

13. En Amicus Curiae dirigido a la Corte Constitucional la Fiscal de la CPI Fatou Bensouda se refirió a "[l]os esfuerzos de Colombia por promover los objetivos del Estatuto de Roma se reflejan en la introducción de una definición de la responsabilidad del mando como una forma de responsabilidad penal aplicable en el marco de la JEP. Sin embargo, la definición de responsabilidad del mando adoptada se aparta sustancialmente de la prevista en el derecho internacional consuetudinario y de la definición del Estatuto de Roma, y por consiguiente podría frustrar los intentos de Colombia de cumplir su deber de investigar y juzgar los crímenes internacionales". (Bensouda, 2017, pág. 5) 
La responsabilidad de mando de los miembros de la Fuerza Pública fue objeto de regulación constitucional (Acto Legislativo 01 de 04 de abril de 2017) y se hizo bajo la determinación de unos elementos específicos que deben ser cumplidos para que haya lugar a la configuración de la responsabilidad. Posteriormente, la responsabilidad de mando de los miembros de las FARC-EP, se reguló a través de una ley estatutaria, también con unos criterios limitados, para que se logre la configuración de este tipo de responsabilidad, sin unas exigencias claras frente a la responsabilidad de los superiores jerárquicos.

A pesar de la inclusión de estas disposiciones al ordenamiento jurídico colombiano, no se visualiza una verdadera voluntad de regulación exhaustiva de la figura, conforme al desarrollo jurisprudencial que se hado en los Tribunales Penales Internacionales y en los Tribunales ad hoc. En particular, los elementos específicos recogidos en el Acto Legislativo 01/2017 y en la ley estatutaria no recogen los desarrollos que se han dado frente al tema en el derecho penal internacional, ni lo establecido en el artículo $28 \mathrm{del}$ Estatuto de Roma. Esto se puede observar en que:

(i) La definición de la Responsabilidad de Mando en el Acto Legislativo y en la Ley Estatutaria contraviene las disposiciones del Estatuto de Roma, en lo relacionado al requisito de control efectivo, al exigir un control sobre la conducta y establecer una serie de condiciones concurrentes que se deben probar para demostrar el control efectivo. (ii) Al existir una serie de elementos subjetivos que deben ser verificados se genera una ambigüedad frente al conocimiento relacionado con la expresión "hubiere debido conocer".

(iii) Nada se dijo en el Acuerdo Final y por consiguiente tampoco en el desarrollo legal, sobre la responsabilidad de los civiles no militares, que en el Estatuto de Roma cuentan con una regulación específica y menos estricta en relación con la responsabilidad de los militares. A pesar de que el proceso de Justicia Transicional en Colombia, permite la aplicación de una serie de disposiciones especiales encaminadas al logro de importantes valores como la paz, también lo es el que existen unos límites en el Derecho internacional de los derechos humanos, en el Derecho Internacional Humanitario y en el Derecho internacional penal, en relación con aquellas conductas consideradas como de mayor gravedad, que no admiten niveles de impunidad, particularmente para los máximos responsables.

Por ello la Fiscalía de la Corte Penal Internacional, a través de la figura del Amicus Curiae y de los Reportes Intermedios, ha manifestado su preocupación en torno a los posibles casos de impunidad de los máximos responsables de los más graves delitos de competencia de la Corte Penal Internacional, como lo son, entre otros, las denominadas ejecuciones extrajudiciales. De esta manera, la regulación de la Jurisdicción Especial de Paz no obsta para que la CPI pueda ejercer su competencia en Colombia, como lo ha venido advirtiendo. 


\section{BIBLIOGRAFÍA}

- Ambos, K. (1999). La responsabilidad del superior en el derecho penal internacional. ADPCP, $L(\mathrm{II})$, 527-593.

- Ambos, K. (2005). La Parte General Del Derecho Penal Internacional, Bases Para Una Elebaoración Dogmática. Montevideu: Konrad Adenauer Siftung.

- Bensouda, F. (2017). International criminal court. Recuperado de http:// cr00.epimg.net/descargables/2017/10/2 1/17135b6061c7a5066ea86fe7e37ce26a. pdf?int=masinfo

- Brook, T. (2001). The Tokyo Judment. The Journal of Asian Studies.

- Cadavid, P. (2013). Coautoría en aparatos organizadosdepoderdecarácterdelincuencial. Bogotá: Grupo Editorial Ibañez.

- CICR. (2017). Jurisdicción Especial para la Paz en Colombia debería incluir el concepto de responsabilidad penal de los superiores en su totalidad. Bogotá: CICR.

- Corte Constitucional. (1995). Sentencia C-578/1995. M.P. Eduardo Cifuentes Muñoz.

- Corte Constitucional. (1997). Sentencia C-285/1997. M.P. CARLOS GAVIRIA DIAZ.

- Corte Constitucional. (2000). Sentencia C-368/2000. M.P. Carlos Gaviria Diaz.

- Corte Constitucional. (2001). SU 1184/2001. Eduardo Montealegre Lynett.

- Corte Constitucional. (2016). Sentencia C-084/2016. M.P. Luis Ernesto Vargas Silva.

- Corte Constitucional. (2016). SENTENCIA C-084/2016. M.P. Luis Ernesto Vargas Silva.

- Corte Suprema de Justicia. (2014). Sentencia SP 7135 de 2014. M.P. Eugenio Fernández Carlier.

- Corte Suprema de Justicia. (2014). SP 14322014 . Gustavo Enrique Malo.

- COURT, I. C. (11 de 2012). www.icc-cpi.int. Recuperado el 18 de 09 de 2017

- Fiscal vs. Jean Paul Akayesu, Caso № ICTR96-4-T (TRIBUNAL INTERNACIONAL PENAL PARA RUANDA 02 de SEPTIEMBRE de 1998).
- Fiscal vs. Zejnil Delalić,Zdravko Mucić alias "Pavo", Hazim Delić,Esad Landžo alias "Zenga" (Čelebići) , Caso № IT-96-21-T (TRIBUNALPENAL INTERNACIONAL PARA LA EX YUGOSLAVIA 16 de noviembre de 1998).

- Fiscal vs.Aleksovski (Tribunal Penal para la Antigua Yugoslavia 25 de junio de 1999).

- Gómez, R. (2017). El plebiscito sobre los acuerdos de la paz en Colombia: La legítima búsqueda de la paz en un contexto político antagónico. Misión Jurídica, 10(13), 265-278.

- HRW. (2015). Análisis de Human Rights Watch sobre el "Acuerdo sobre las Víctimas del Conflicto".

- HRW. (25 de 01 de 2017). www.hrw.org. Recuperado el 20 de 09 de 2017

- Internacional, C. P. (1998). Estatuto de la corte penal internacional.

- Internacional, C. P. (2016). Informe Preliminar Situación Colombia.

- Jakobs, G. (2000). El ocaso del dominio del hecho. BARCELONA: Conferencias sobre temas penales.

- Ley 599. (2000). Congreso de la República.

- Mucić et al., (1996). (IT-96-21) (International Criminal Tribunal for the former Yugoslavia 19 de 03 de

- Olásolo, H. (2013). Tratado de autoría y participación en el derecho penal internacional. Valencia: tirant.

- Olasolo, H., y Canosa , J. (2018). La inseguridad jurídica de los acuerdos de paz a la luz del régimen jurídico internacional de los Crímenes de ius cogens y la justicia de transición. Polít. crim., 13(25).

- Paz, 0. d. (2016). Cambios precisiones y ajustes para un nuevo acuerdo final. La Habana, Cuba.

- Perez- León, J. (2007). La responsabilidad del superior "sensu estricto" por crímenes de guerra en el derecho internacional contemporaneo. Internacional Law, 161.

- Presidencia - Farc-Ep. (2016). Acuerdo final para la terminación del conflcito y la 
construcción de una paz estable y duradera. Bogotá: OACP.

- Prosecutor v. Martic, (1996). Caso No. IT85-11. Tribunal internacional penal para la exYugoslavia

- RIGHTS, E. C. (2017). AMICUS CURIAE. BERLÍN: ECCHR.

- Roxin, C. (1998). El dominio de organización como forma independiente de autoría mediata. Dominio, 243-245.

- Senado. (2017). Proyecto de Ley 08 de 2017. Gaceta 626 de 2017.

- Situation in the Central African Republic in the case of the Prosecutor v Jean Pierre Bemba Gombo. (2016). icc-01/05-01/08 (corte penal internacional)
- SP 7135-2014, 35113 (Corte Suprema de Justicia ).

- SP1432-2014, 40214 (Corte Suprema de Justicia 19 de febrero de 2014).

- SU 1184-01 (Corte Constitucional 13 de 11 de 2001).

- The Prosecutor vs Tiomir Blaskic., (2000). it-95-14-t (tribunal internacional penal para la ex-Yugoslavia

- UN. (2000). legal.un.org. Recuperado de http://legal.un.org/avl/pdf/ha/scsl/scsl_s.pdf

- USVSVon Leeb. (1948). Case № 72 (Tribunal interncional penal para nuremberg)

- US VS Von Leeb.. (1948) Case № 7 (Tribunal interncional penal para nuremberg ) 